\title{
TANGGUNG JAWAB PERUSAHAAN JASA EKSPEDISI TERHADAP KERUSAKAN BARANG KIRIMAN MILIK KONSUMEN (STUDI PADA NINJA XPRESS)
}

\author{
Dewa Kadek Kevin Patria, Fakultas Hukum Universitas Udayana, \\ e-mail: kevinpatria11@gmail.com \\ I Gde Putra Ariana, Fakultas Hukum Universitas Udayana, \\ e-mail: putra_ariana@unud.ac.id \\ doi: https://doi.org/10.24843/KS.2020.v08.i09.p07
}

\begin{abstract}
ABSTRAK
Jurnal ini ditulis dengan tujuan untuk mengetahui pertanggungjawaban perusahaan jasa ekspedisi Ninja Xpress atas kerusakan pada barang kiriman milik konsumen. Jurnal ini ditulis menggunakan metode penelitian hukum empiris dengan pendekatan fakta dan perundang-undangan. Hasil penelitian menunjukkan bahwa pihak Ninja Xpress memberikan ganti kerugian berupa pengembalian dana sebesar 10 kali biaya jasa dan tidak lebih dari Rp 1.000.000,00 untuk barang kiriman yang tidak diasuransikan. Apabila diasuransikan maka ganti rugi senilai harga barang sesuai nilai barang. Pengguna jasa dapat mengajukan klaim ganti rugi melalui e-mail ke support_id@ninjavan.co atau mendatangi kantor Ninja Xpress terdekat dengan membawa bukti berupa identitias pengirim, bukti tanda kiriman barang, polis asuransi yang selanjutnya akan dicocokan dengan arsip yang dimiliki oleh Ninja Xpress.
\end{abstract}

Kata Kunci:, tanggung jawab, perusahaan jasa ekspedisi, kerusakan barang, konsumen

\begin{abstract}
The purpose of writing this journal is to find out how the implementation of forms of responsibility for damaged goods belonging to consumers by the Ninja Xpress shipping company.. This journal is written using empirical legal research methods with a fact and legislation approach. The conclusion of this journal is that Ninja Xpress provides compensation in the form of a refund of 10 times the service fee and no more than $R p 1,000,000.00$ for shipment that is not insured. If insured, the compensation is equal to the price of the goods according to the value of the goods. Service users can submit compensation claims by e-mail to support_id@ninjavan.co or go to the nearest Ninja Xpress office by bringing proof in the form of a sender's identity, proof of shipment, proof of insurance policies which will then be matched with archives owned by Ninja Xpress.
\end{abstract}

Keywords: responsibilities, Goods Delivery,

\section{Pendahuluan}

1.1. Latar Belakang

Meningkatnya jumlah penduduk menyebabkan intensitas kebutuhan manusia turut meningkat. Kegiatan pemenuhan kebutuhan harian manusia tentu perlu melakukan interaksi dengan orang lain, salah satunya yaitu melalui proses jual-beli. Aktifitas jual-beli merupakan bagian yang tidak terpisahkan dari dunia perdagangan. Jual-beli dapat didefinisikan sebagai proses tukar menukar, dalam hal ini yang ditukar adalah uang dengan barang dan/atau jasa. Umumnya, proses jual beli oleh kedua belah pihak dilakukan dengan saling bertemu/bertatap muka secara langsung. 
Perkembangan teknologi terjadi sangat cepat di berbagai bidang. Salah satu contohnya yaitu penggunaan internet (kependekan dari interconnection-networking). Penggunaan internet ini memudahkan manusia dalam mengakses informasi serta melakukan komunikasi dengan sangat mudah, cepat, dan murah. Konsumen sangat dimudahkan dalam memenuhi kebutuhannya dengan adanya internet. Konsumen tidak perlu pergi kemana-mana, hanya perlu duduk sambil mengakses internet melalui media elektronik untuk melihat barang-barang yang ditawarkan para pedagang di internet, setelah konsumen setuju untuk membeli barang melalui internet, maka pedagang akan mengirim barang dengan memanfaatkan jasa pengiriman barang ke alamat konsumen. Sudah menjadi kebutuhan bagi masyarakat menggunakan jasa pengangkutan barang dalam melakukan kegiatan usahanya atau saat ingin mengirim sesuatu ke suatu tempat. Jasa pengiriman barang menjadi sebuah jasa yang banyak diminati oleh masyarakat saat melakukan kegiatan jual-beli dengan jarak yang cukup jauh. Hadirnya perusahan jasa pengiriman barang (perusahaan jasa ekspedisi) ini sangat mempermudah proses jual beli karena mampu mengefisiensikan waktu serta biaya. Pengiriman barang oleh pihak pengirim kepada pihak penerima bisa dikategorikan sebagai suatu perjanjian pengangkutan.

Definisi pengangkutan menurut H.M.N. Purwosutjipto yaitu perjanjian secara timbal-balik yang dilakukan oleh pengangkut dan pengirim dimana pengangkut berkewajiban untuk melakukan kegiatan pengangkutan dari tempat pengirim sampai tiba di tujuan yang dikehendaki dengan utuh sesuai perjanjian dan pihak pengirim wajib untuk membayarkan sejumlah uang yang telah ditentutakn sebagai biaya angkutan. ${ }^{1}$ Kegiatan pengangkutan barang yang dilaksanakan oleh jasa ekspedisi harus dapat menjamin keamanan dari barang kiriman milik pengguna jasa agar tiba ditujuan dalam kondisi utuh/sama seperti saat barang tersebut dikirimkan.

Salah satu perusahaan jasa pengiriman yang memiliki jangkauan pengiriman ke seluruh Indonesia adalah Ninja Xpress. Ninja Xpress merupakan salah satu perusahaan pengiriman yang berbasis teknologi yang memberikan layanan pengiriman barang maupun dokumen ke seluruh wilayah dalam jangkauan Ninja Xpress. Ninja Xpress memiliki jaringan di enam negara di kawasan Asia Tenggara salah satunya yaitu Indonesia. Pengguna jasa hanya perlu membayarkan sejumlah uang kepada Ninja Xpress sebagai biaya untuk mengirim barang ke alamat yang telah ditentukan. Namun dibalik kemudahan yang diberikan oleh penyedia jasa ekspedisi, tidak dapat dipungkiri juga bahwa ada kendala-kendala yang dialami selama proses pengiriman yang dapat menimbulkan kerugian bagi konsumen. Salah satu peristiwa merugikan yang kerap terjadi yaitu barang kiriman sampai di tujuan dengan kondisi rusak atau diterima dalam kondisi tidak utuh sesuai pada saat barang tersebut dikirimkan. Mengacu pada Pasal 7 huruf F Undang-Undang Nomor 8 Tahun 1999 tentang Perlindungan Konsumen maka perusahaan jasa ekspedisi memiliki tanggung jawab atas kejadian rusaknya barang milik konsumen saat proses pengiriman yang dilaksanaka. Dengan adanya peristiwa tersebut pengguna jasa akan dirugikan karena pihaknya telah membayarkan sejumlah uang untuk mendapatkan pelayanan yang diinginkan yaitu agar barang kiriman sampai ditujuan dengan kondisi utuh seperti saat barang dikirimkan.

1 Sagita, Putu Ari, and I. Nyoman Wita. "KEABSAHAN JASA PENGANGKUTAN OJEK ONLINE DI INDONESIA." Kertha Semaya: Journal Ilmu Hukum 7, no. 11(2019): 1-14. 
Beranjak dari kejadian tersebut, maka penulis tertarik untuk membahas bagaimana pertanggungjawaban perusahaan ekspedisi Ninja Xpress atas kerusakan pada barang kiriman milik konsumen.

\subsection{Permasalahan}

Permasalahan yang akan diangkat dalam tulisan ini yaitu:

1. Bagaimana pertanggungjawaban Ninja Xpress atas terjadinya kerusakan pada barang kiriman milik konsumen?

2. Apa upaya yang dapat ditempuh konsumen yang dirugikan dalam menuntut ganti rugi kepada Ninja Xpress?

\subsection{Tujuan}

Tulisan ini disusun dengan tujuan untuk mengetahui bentuk pertanggungjawaban perusahaan ekspedisi Ninja Xpress atas kerusakan pada barang kiriman milik konsumen serta untuk mengkaji upaya apa yang dapat ditempuh konsumen untuk menuntuk ganti rugi atas kerugian yang dialami akibat dari kerusakan barang yang disebabkan oleh Perusahaan Ekspedisi Ninja Xpress.

\section{Metode Penelitian}

Metode yang digunakan dalam tulisan ini yaitu metode penelitian hukum empiris yang bertujuan untuk melakukan analisa mengenai seberapa efektif suatu peraturan perundang-undangan berlaku di masyarakat. ${ }^{2}$ Pendekatan yang digunakan yaitu pendekatan fakta dan pendekatan perundang-undangan. Pendekatan fakta (The Fact Approach) yaitu dengan mengumpulkan fakta-fakta yang terdapat di lapangan sedangkan pendekatan perundang-undangan (Statute Approach) dengan mengidentifikasi peraturan perundang-undangan yang terkait permasalahan pada jurnal ini yaitu Undang-Undang Nomor 8 Tahun 1999 tentang Perlindungan Konsumen. Teknik analisis data dalam jurnal ini yaitu menggunakan teknik analisis kualitatif, artinya data yang didapatkan baik tertulis maupun lisan yang kemudian diberikan uraian-uraian yang bersifat penjelasan terhadap data yang diperoleh lalu disusun dengan baik sehingga mendapatkan suatu kesimpulan atas permasalahan dalam jurnal ini.

\section{Hasil dan Pembahasan}

3.1 Pertanggungjawaban Ninja Xpress Atas Terjadinya Kerusakan pada Barang Kiriman Milik Konsumen

Perjanjian merupakan perbuatan yang dilakukan antara satu orang atau lebih untuk bersepakat mengikatkan diri satu dengan yang lain. Pengiriman barang oleh pihak pengirim kepada pihak penerima bisa dikategorikan sebagai suatu perjanjian pengangkutan. ${ }^{3}$ Pengangkutan yaitu perjanjian yang dilakukan secara timbal-balik antara pengangkut dan pengirim, pengangkut berkewajiban melakukan kegiatan pengangkutan dari tempat pengirim hingga tiba di tujuan yang telah disepakati dengan utuh sesuai perjanjian sedangkan pihak pengirim wajib untuk membayar

2 Bambang S., METODOLOGI PENELITIAN HUKUM, (Jakarta, Rajagrafindo Persada, 2006), 18.

3 Sari, Ni Putu Puspa Chandra, and I. Nyoman Suyatna. "Perlindungan Konsumen Pengguna Angkutan Barang Melalui Layanan Ojek Online." Kertha Semaya: Journal Ilmu Hukum 6, no. 9 (2018): $1-5$. 
sejumlah uang sebagai biaya angkutan. ${ }^{4}$ Perjanjian yang baik harus dibuat secara sadar oleh para pihak serta tanpa ada tekanan apapun dan wajib memenuhi syarat sahnya perjanjian yang telah ditentukan, yaitu:

1. Adanya kata sepakat dari para pihak;

2. Kecakapan untuk membuat suatu perikatan;

3. suatu hal tertentu;

4. suatu sebab yang tidak dilarang. ${ }^{5}$

Pasal 468 KUHD mengatur mengenai pengangkutan dimana pihak pengangkut wajib menjaga keamanan barang milik konsumen agar tetap utuh dimulai ketika barang diserahkan hingga pada saat barang diserahkan di tujuan. Tidak dapat dipungkiri juga bahwa ada kendala-kendala yang dialami selama proses pengiriman yang dapat menimbulkan kerusakan, keterlambatan pengiriman, bahkan sampai terjadi kehilangan barang milik konsumen. Perusahaan jasa berkewajiban untuk bertanggung jawab terhadap kerugian yang diderita konsumen. Ada beberapa prinsip tanggung jawab dalam pengangkutan, yaitu :

1. Prinsip tanggung jawab berdasarkan atas dasar unsur kesalahan (fault liability principle);

2. Prinsip tanggung jawab berdasarkan atas praduga (presumption of liability principle);

3. Prinsip tanggungjawab mutlak (absolute liability principle). ${ }^{6}$

Prinsip tanggungjawab yang dianut di Indonesia yaitu tanggungjawab berdasarkan atas praduga, artinya dari setiap kerugian yang terjadi akibat kegiatan pengangkutan merupakan tanggungjawab dari pengangkut. ${ }^{7}$ Kecuali apabila pihak pengangkut dapat membuktikan bahwa kerugian yang terjadi bukan akibat dari kesalahannya, maka ia dapat terhindar dari kewajiban membayar ganti kerugian, sesuai ketentuan pasal 468 ayat (2), 477, dan 522 ayat (2) KUHD.

Seseorang berkewajiban untuk memberikan ganti rugi atas perbuatan melanggar hukum dan kerugian yang ditimbulkan atas kesalahannya. Ada beberapa hal yang menentukan apakah suatu perbuatan termasuk perbuatan melawan hukum yaitu:

1. Tidak sesuai dengan undang-undang;

2. Melanggar hak subjektif orang lain;

3. Tidak sesuai dengan kesusilaan;

4. Bertentangan dengan kepatutan dalam masyarakat. ${ }^{8}$

Berdasarkan Pasal 468 KUHD, pengangkut harus bertanggung jawab atas kerugian yang timbul akibat rusaknya barang, kecuali jika dapat dbuktikan bahwa rusaknya barang tersebut merupakan akibat dari suatu kejadian diluar kuasa pihak

4 Sagita, Putu Ari, and I. Nyoman Wita. Loc. Cit.

5 PUTRI, KADEK AYU ANGGRENI, AA KETUT SUKRANATHA, and I. MADE PUJAWAN. "TANGGUNG JAWAB PERUSAHAAN ANGKUTAN DARAT TERHADAP BARANG KIRIMAN APABILA MENGALAMI KERUSAKAN (STUDI PADA PT. GED DENPASAR BALI)." Kertha Semaya : Journal Ilmu Hukum 4, no. 1 (2018): 1-11.

6 PRIHANTINI, Made Bella Meisya; PARSA, I Wayan. "PERLINDUNGAN KONSUMEN TERKAIT PEMBATALAN SECARA SEPIHAK VOUCHER HOTEL OLEH PELAKU USAHA TRAVELOKA." Kertha Semaya : Journal Ilmu Hukum 7, no. 5 (2019): 1-15.

7 Anantyo, Sendy, and Budiharto Herman Susetyo. "TANGGUNG JAWAB PENGANGKUT TERHADAP BARANG MUATAN PADA PENGANGKUTAN MELALUI LAUT." Diponegoro Law Journal 1, no. 4 (2012): 1-6

8 Suharnoko, Hukum Perjanjian Teori dan Analisa Kasus, (Jakarta, Kencana, 2009), 117 
pengangkut (force majeur). ${ }^{9}$ Pasal 472 KUHD menentukan besarnya ganti kerugian yaitu sesuai dengan nilai barang ketika barang itu pertama kali diterima.

Pasal 7 huruf f Undang-Undang No. 8 Tahun 1999 tentang Perlindungan Konsumen (UUPK) menyebutkan kewajiban dari pelaku usaha adalah memberikan ganti kerugian yang timbul akibat pemanfaatan jasa yang diperdagangkan. Pasal 19 menjelaskan lebih rinci bahwa perusahaan jasa ekspedisi diwajibkan memberikan ganti kerugian atas kerusakan pada barang kiriman milik konsumen dalam bentuk sejumlah uang sesuai dengan harga barang atau mengganti dengan barang yang setara. Perusahaan jasa ekspedisi selaku pelaku usaha harus memberikan pertanggungjawaban ketika proses pengiriman barang yang dilakukan menimbulkan kerugian bagi konsumen akibat dari ada hak konsumen yang dilanggar. ${ }^{10}$

PT. Andiarta Muzizat atau Ninja Xpress didirikan pertama kali di Singapura pada tahun 2014 dan hingga saat ini telah memiliki enam jaringan di kawasan Asia Tenggara, salah satunya adalah di Indonesia. Berdasarkan hasil wawancara dengan Bapak Angga Nugraha selaku customer service di Ninja Xpress, upaya yang dilakukan oleh Ninja Xpress dalam rangka memberikan perlindungan bagi pengguna jasanya yaitu dengan menawarkan asuransi pada barang yang akan dikirimkan. Dengan adanya asuransi tersebut, maka Ninja Xpress akan meningkatkan kinerjanya sehingga proses pengiriman barang lebih terjamin. Adanya asuransi tersebut membuat Ninja Xpress memiliki tanggung jawab penuh atas suatu barang kiriman yang diberikan asuransi, sehingga ketika terjadi hal-hal yang menyebabkan objek pengiriman mengalami kerusakan maka Ninja Xpress akan mengganti rugi sesuai dengan harga dari barang kiriman yang diasuransikan. Ninja Xpress dapat terbebas dari tanggung jawabnya dalam memberikan ganti rugi jika pihaknya bisa membuktikan bahwa kerugian tersebut timbul bukan akibat dari kesalahannya atau disebabkan oleh keadaan diluar kendali (force majeur).

Bentuk pertanggungjawaban yang diberikan pihak Ninja Xpress adalah dengan mengembalikan dana sebesar 10 (sepuluh) kali dari biaya jasa yang digunakan atau maksimal sampai $\operatorname{Rp} 1.000 .000,00$ (satu juta rupiah) jika pengirim tidak mengasuransikan barang kirimannya. Sebagai contoh, jika biaya pengiriman barang sebesar Rp 16.000 (enam belas ribu rupiah) maka besar dana yang dikembalikan sebagai bentuk ganti rugi adalah senilai Rp 160.000 (seratus enam puluh ribu rupiah), bukan sebesar Rp. 1.000 .000 (satu juta rupiah). Lain halnya jika pengirim mengasuransikan barang kirimannya, maka kerusakan barang yang disebabkan oleh kesalahan dari Ninja Xpress akan diganti senilai dengan harga barang kiriman tersebut (berdasarkan struk pembelian barang). Ganti rugi dilakukan oleh Ninja Xpress untuk menjaga kepercayaan para pengguna jasa pengiriman Ninja Xpress. Pihak Ninja Xpress menganjurkan kepada setiap pelanggannya untuk mengasuransikan barang kirimannya, apalagi jika barang yang akan dikirim memiliki nilai yang tinggi. Hal ini sebagai upaya preventif yang bertujuan untuk melindungi konsumen dari risiko yang dapat terjadi selama proses pengiriman berlangsung. Biaya asuransi yang dibebankan

9 DWIYANTARA M, I Gusti Agung Ryan; SARJANA, I Made. "PERTANGGUNGJAWABAN PT.CITRA VAN TITIPAN KILAT ATAS LEWATNYA WAKTU TUJUAN PENGIRIMAN MAKANAN DI KOTA DENPASAR." Kertha Semaya: Journal Ilmu Hukum 6, no. 2, (2019): 114.

10 Agastya, Ida Bagus Ketut, I. Made Udiana, and Anak Agung Ketut Sukranatha. "PERLINDUNGAN HUKUM TERHADAP PENGGUNA JASA PENGIRIMAN BARANG DENGAN KENDARAAN BERMOTOR UMUM PADA PT. PAHALA EXPRESS DELIVERY DENPASAR." Kertha Semaya: Journal Ilmu Hukum 7, no. 12 (2019): 1-15. 
untuk barang dengan nilai di bawah Rp 1.000 .000 (satu juta rupiah) adalah sebesar Rp 2.500 (dua ribu lima ratus rupiah). Sedangkan untuk barang dengan nilai lebih dari Rp 1.000 .000 (satu juta rupiah) akan dibebankan biaya asuransi sebsar 0,25\% dari nilai barang. (wawancara 05 Mei 2020)

Kasus terkait kerusakan barang yang pernah terjadi pada Ninja Xpress yaitu kasus kerusakan paket kiriman berupa beberapa toples kue dan makanan yang dikirim oleh Ibu Suartini dengan tujuan Denpasar-Singaraja. Barang kiriman tersebut tidak diasuransikan oleh Ibu Suartini sehingga saat mengajukan klaim ganti rugi, pihak Ninja Xpress tidak memberikan ganti rugi secara penuh melainkan hanya mengganti 10 (sepuluh) kali biaya pengiriman yang dibayar oleh Ibu Suartini.

Hal ini menunjukan bahwa ada upaya pelaksanaan Pasal 468 KUHD dan Pasal 19 UUPK oleh Ninja Xpress yang menentukan bahwa pihaknya harus memberikan ganti rugi apabila ada kerusakan pada barang pada saat pengiriman berlangsung, akan tetapi ganti rugi yang diberikan tidak penuh apabila tidak dibarengi dengan asuransi.

\subsection{Upaya Yang Dapat Ditempuh Pengguna Jasa Ninja Xpress Dalam Menuntut Ganti Rugi}

Jaminan yang diberikan oleh suatu perusahaan bagi pengguna jasa maupun produk yang diperdagangkan merupakan hal yang sangat penting. Dalam rangka menjamin terpenuhinya hak-hak dari masyarakat maka diperlukan adanya suatu perlindungan hukum. Menurut Kamus Besar Bahasa Indonesia, perlindungan diartikan sebagai tempat berlindung, hal yang melindungi. ${ }^{11}$ Mochtar Kusumaatmadja mengartikan hukum sebagai keseluruhan kaidah dan asas yang mengatur pergaulan dalam bermasyarakat dan bertujuan untuk memelihara ketertiban.12 Menurut Satjipto Raharjo perlindungan hukum adalah upaya memberikan pengayoman kepada hakhak masyarakat yang dirugikan agar mereka dapat menikmati semua hak-hak yang diberikan oleh hukum. ${ }^{13}$ Perlindungan hukum sebagai upaya pemenuhan hak masyarakat sehingga memberikan rasa aman kepada masyarakat. ${ }^{14}$ UUPK lahir untuk memberikan perlindungan bagi hak-hak yang dimiliki konsumen dan pelaku usaha. Dalam UUPK, perlindungan konsumen merupakan upaya dalam memberikan jaminan kepastian hukum bagi konsumen dalam mengkonsumsi barang dan/atau jasa yang diperdagangkan. ${ }^{15}$ Az. Nasution mengartikan hukum perlindungan konsumen sebagai "kaidah-kaidah hukum yang mengatur hubungan dan masalah antara berbagai pihak satu sama lain berkaitan dengan barang dan/atau jasa konsumen, di dalam pergaulan hidup."16

Konsumen memiliki hak dalam menuntut ganti kerugian dari pelaku usaha apabila mendapatkan pelayanan tidak sesuai dengan yang disepakati sehingga

11 Perlindungan. (2016). KBBI Daring., https://kbbi.kemdikbud.go.id/entri/perlindungan. diakses pada tanggal 10 Mei 2020.

12 Zulham, Hukum Perlindungan Konsumen, (Jakarta, Kencana, 2016), 4.

13 Ibid. H. 2

14 Dwipa, Komang Calvin Krisna, and Ni Luh Gede Astariyani. "PEMBATALAN TIKET HOTEL ONLINE SECARA SEPIHAK OLEH PIHAK AGODA?." Kertha Semaya: Journal Ilmu Hukum 7, no. 9 (2019): 1-14.

15 Pasal 1 angka 1 Undang-Undang Nomor 8 Tahun 1999 tentang Perlindungan Konsumen.

16 Njatrijani, Rinitami. "Posisi Undang-Undang Perlindungan Konsumen Nomor 8 Tahun 1999 dalam Upaya Perlindungan Terhadap Konsumen." Diponegoro Private Law Review 1, no. 1 (2017): 23-35. 
menyebabkan kerugian baginya. ${ }^{17}$ Tindakan konsumen dalam melakukan klaim ganti rugi kepada pelaku usaha tersebut diatur dalam Pasal 4 UUPK yang menjabarkan tentang hak-hak yang diperoleh oleh pihak konsumen, dalam huruf $\mathrm{h}$ dijelaskan bahwa konsumen berhak diberikan ganti rugi jika sebuah jasa yang diberikan tidak sesuai dengan hal yang sudah diperjanjikan atau tidak sebagaimana mestinya. ${ }^{18}$ Ninja Xpress memiliki kewajiban untuk mengantarkan barang kiriman milik konsumen sampai di tujuan dengan kondisi yang utuh sesuai pada saat barang tersebut akan dikirim, namun jika dalam proses pengiriman terjadi hal-hal yang mengakibatkan barang kiriman tersebut mengalami kerusakan maka konsumen berhak menerima ganti kerugian dari Ninja Xpress akibat peristiwa tersebut. Pasal 45 ayat (2) UUPK menyebutkan ada 2 (dua) jalur yang dapat ditempuh dalam upaya menyelesaikan sengketa antara pelaku usaha dengan konsumen yaitu melalui jalur litigasi (pengadilan) dan non litigasi (di luar pengadilan). ${ }^{19}$ Bapak Angga Nugraha mengatakan bahwa Ninja Xpress selalu mengutamakan penyelesaian sengketa melalui jalur kekeluargaan atau negosiasi secara damai antara pihak Ninja Xpress dan konsumen. Sehingga upaya hukum yang dilakukan dalam menyelesaikan sengketa antara Ninja Xpress dan konsumen yaitu menggunakan cara negosiasi yang berarti penyelesaian di luar pengadilan. Pihak yang mengalami kerugian setelah menggunakan jasa pengiriman Ninja Xpress dapat mengajukan klaim ganti rugi melalui surat elektronik (e-mail) ke support_id@ninjavan.co atau mendatangi kantor Ninja Xpress terdekat dengan menunjukkan bukti adanya kerugian yang dialami, serta melengkapi bukti berupa identitias pengirim, bukti tanda kiriman barang, polis asuransi (apabila diasuransikan) yang selanjutnya akan dicocokan dengan arsip yang dimiliki oleh Ninja Xpress.

\section{Kesimpulan}

Berdasarkan uraian pembahasan diatas maka dapat disimpulkan bahwa Ninja Xpress sebagai pelaku usaha jasa pengiriman barang bertanggung jawab atas suatu barang kiriman sejak barang tersebut diterima oleh pihaknya hingga barang tersebut tiba di tujuan sesuai dengan perjanjian. Ninja Xpress menawarkan fasilitas asuransi sebagai upaya perlindungan preventif bagi konsumennya. Apabila saat proses pengiriman terjadi kerusakan pada barang milik konsumen yang secara nyata merupakan kesalahan dari pihak Ninja Xpress, maka pihak Ninja Xpress memberikan ganti rugi sebagai bentuk tanggung jawabnya sebesar 10 (sepuluh) kali biaya jasa atau maksimal senilai Rp 1.000.000,00 (satu juta rupiah) apabila pengirim tidak mengasuransikan barang kirimannya. Jika pengirim menggunakan asuransi, maka ganti rugi yang diberikan seharga barang (berdasarkan struk pembelian barang). Upaya yang ditempuh dalam penyelesaian sengketa antara Ninja Xpress dan konsumen adalah dengan melakukan negosiasi secara damai. Tindakan yang dapat

17 Anak Agung Ayu Krisnanti Larasati, Made Maharta Yasa, 2019, "PERTANGGUNGJAWABAN GOJEK AKIBAT KEHILANGAN BARANG PADA FITUR GOSEND SEBAGAI LAYANAN YANG DITAWARKAN DALAM GOJEK INDONESIA", Jurnal Kertha Semaya 7, no. 12 (2019): 1-12.

18 Wijaya, Edward, and Made Suksma Prijandhini Devi Salain. "UPAYA PENYELESAIAN DALAM PERJANJIAN PENGIRIMAN BARANG YANG DILAKUKAN OLEH UD JAYA KACA DENPASAR." Kertha Semaya: Journal Ilmu Hukum 4, no. 1 (2015): 1-5.

19 Amira, Fida. "Tanggung Jawab Pengiriman Barang Ekspedisi Atas Kehilangan dan/atau Kerusakan Barang Berdasarkan Undang-undang Nomor 38 Tahun 2009 Tentang Pos (Studi Kasus di Kantor Pos Solo)." Privat Law 4, no. 1 (2016): 117-124. 
dilakukan oleh konsumen yang dirugikan yaitu dengan mengajukan klaim ganti rugi atas kerusakan barang dengan cara menghubungi pihak Ninja Xpress melalui surat elektronik (e-mail) ke support_id@ninjavan.co atau mendatangi langsung kantor Ninja Xpress terdekat dengan membawa bukti adanya kerugian yang dialami serta melengkapi bukti berupa identitias pengirim, bukti tanda kiriman barang, polis asuransi apabila diasuransikan. Kepada Ninja Xpress hendaknya memberikan ganti rugi penuh bagi konsumen yang mengalami kerugian atas kerusakan pada barang kiriman tanpa perlu menambah biaya lain lagi seperti asuransi serta meningkatkan kinerjanya agar tidak terjadi kembali kejadian-kejadian yang dapat menimbulkan kerugian bagi konsumen.

\section{DAFTAR PUSTAKA}

Buku

Bambang S., METODOLOGI PENELITIAN HUKUM, (Jakarta, Rajagrafindo Persada, 2006), 18.

Suharnoko, Hukum Perjanjian Teori dan Analisa Kasus, (Jakarta, Kencana, 2009).

Zulham, Hukum Perlindungan Konsumen, (Jakarta, Kencana, 2016)

\section{Jurnal}

Agastya, Ida Bagus Ketut, I. Made Udiana, and Anak Agung Ketut Sukranatha. "PERLINDUNGAN HUKUM TERHADAP PENGGUNA JASA PENGIRIMAN BARANG DENGAN KENDARAAN BERMOTOR UMUM PADA PT. PAHALA EXPRESS DELIVERY DENPASAR." Kertha Semaya: Journal Ilmu Hukum 7, no. 12 (2019), 1-15.

Amira, Fida. "Tanggung Jawab Pengiriman Barang Ekspedisi Atas Kehilangan dan/atau Kerusakan Barang Berdasarkan Undang-undang Nomor 38 Tahun 2009 Tentang Pos (Studi Kasus di Kantor Pos Solo)." Privat Law 4, no. 1 (2016), 117-124.

Anak Agung Ayu Krisnanti Larasati, Made Maharta Yasa, "PERTANGGUNGJAWABAN GOJEK AKIBAT KEHILANGAN BARANG PADA FITUR GO-SEND SEBAGAI LAYANAN YANG DITAWARKAN DALAM GOJEK INDONESIA", Jurnal Kertha Semaya 7, no. 12 (2019), 1-12.

Anantyo, Sendy, and Budiharto Herman Susetyo. "TANGGUNG JAWAB PENGANGKUT TERHADAP BARANG MUATAN PADA PENGANGKUTAN MELALUI LAUT." Diponegoro Law Journal 1, no. 4 (2012), 1-6.

Dwipa, Komang Calvin Krisna, and Ni Luh Gede Astariyani. "PEMBATALAN TIKET HOTEL ONLINE SECARA SEPIHAK OLEH PIHAK AGODA?." Kertha Semaya: Journal Ilmu Hukum 7, no. 9 (2019), 1-14.

DWIYANTARA M, I Gusti Agung Ryan; SARJANA, I Made. "PERTANGGUNGJAWABAN PT.CITRA VAN TITIPAN KILAT ATAS LEWATNYA WAKTU TUJUAN PENGIRIMAN MAKANAN DI KOTA DENPASAR." Kertha Semaya: Journal Ilmu Hukum 6, no. 2, (2019), 1-14.

Njatrijani, Rinitami. "Posisi Undang-Undang Perlindungan Konsumen Nomor 8 Tahun 1999 dalam Upaya Perlindungan Terhadap Konsumen." Diponegoro Private Law Review 1, no. 1 (2017), 23-35.

PRIHANTINI, Made Bella Meisya; PARSA, I Wayan. "PERLINDUNGAN KONSUMEN TERKAIT PEMBATALAN SECARA SEPIHAK VOUCHER HOTEL OLEH PELAKU USAHA TRAVELOKA." Kertha Semaya : Journal Ilmu Hukum 7, no. 5 (2019), 1-15. 
PUTRI, KADEK AYU ANGGRENI, AA KETUT SUKRANATHA, and I. MADE PUJAWAN. "TANGGUNG JAWAB PERUSAHAAN ANGKUTAN DARAT TERHADAP BARANG KIRIMAN APABILA MENGALAMI KERUSAKAN (STUDI PADA PT. GED DENPASAR BALI)." Kertha Semaya : Journal Ilmu Hukum 4, no. 1 (2018), 1-11.

Sagita, Putu Ari, and I. Nyoman Wita. "KEABSAHAN JASA PENGANGKUTAN OJEK ONLINE DI INDONESIA." Kertha Semaya: Journal Ilmu Hukum 7, no. 11(2019), 114.

Sari, Ni Putu Puspa Chandra, and I. Nyoman Suyatna. "Perlindungan Konsumen Pengguna Angkutan Barang Melalui Layanan Ojek Online." Kertha Semaya: Journal Ilmu Hukum 6, no. 9 (2018), 1-5.

Wijaya, Edward, and Made Suksma Prijandhini Devi Salain. "UPAYA PENYELESAIAN DALAM PERJANJIAN PENGIRIMAN BARANG YANG DILAKUKAN OLEH UD JAYA KACA DENPASAR." Kertha Semaya: Journal Ilmu Hukum 4, no. 1 (2015), 1-5.

\section{INTERNET}

KBBI Daring., https://kbbi.kemdikbud.go.id/entri/perlindungan. diakses pada tanggal 10 Mei 2020.

\section{PERATURAN PERUNDANG-UNDANGAN}

Kitab Undang-Undang Hukum Perdata

Kitab Undang-Undang Hukum Dagang

Undang-Undang Nomor 8 Tahun 1999 tentang Perlindungan Konsumen, Lembaran Negara Republik Indonesia Tahun 1999 Nomor 22, Tambahan Lembaran Negara Republik Indonesia Nomor 3821. 